\title{
O SENTIDO OLFATO NO CUIDADO DE ENFERMAGEM HOSPITALAR
}

\author{
The olfactory sense in a hospital nursing care. \\ El sentido olfato en la atención de enfermería hospitalar
}

Sílvia Teresa Carvalho de Araújo

Lys Eiras Cameron²

Lilian Felippe Duarte de Oliveira ${ }^{3}$

\section{RESUMO}

0 objetivo deste estudo foi identificar as percepções e reações relacionadas ao sentido olfato durante o cuidado. Apresenta 0 resultado de três pesquisas de doutorado sobre as pistas olfativas na compreensão das alterações clínicas e padrão de cuidado de enfermagem em setores hospitalares. Estudo exploratório, descritivo, com abordagem qualitativa valorizando princípios do método Sociopoético e dos Sentidos Sociocomunicantes do Corpo. Os sujeitos utilizam o sentido olfato como instrumento para: diagnosticar os desvios de saúde fisiológicos e psicoafetivos; avaliar o estado de higiene, de limpeza corporal do paciente e do ambiente; e nortear o cuidado de enfermagem necessário. Identificamos repulsa pelo mau odor que emana do paciente e as estratégias utilizadas para minimizá-lo. Possibilitou-se instituir um espaço de diálogo para conhecer as reações aos odores, reconhecer as próprias limitações aos estímulos olfativos e redimensionar os mecanismos de respostas que possibilitem o confor to e a segurança dos envolvidos no cuidado de enfermagem.

Palavras-chave: Olfato. Percepção olfatória. Cuidados de Enfermagem. Estudantes de Enfermagem.

\begin{abstract}
The goal is to identify the perceptions and reactions related to the olfactory sense in the care provided. It presents the results of three doctoral researches on olfactory cues in understanding the clinical and standard variations of nursing care in hospital sectors. It's an exploratory and descriptive study with a qualitative approach, emphasizing the principles of Sociopoetic method and the body socio-communicating senses. It shows the use of this as a tool to diagnose the physiological and psychoaffective health deviations; assess the state of hygiene, the cleaning of patient's body and environment and to guide the nursing care needed. It was identified the repulse for the bad smell emanating from the patient and the strategies used to minimize them. Allowed to set up a space for dialogue to see the reactions to odors, recognize their own limitations on olfactory stimuli and adjust the response mechanisms that enable the comfort and safety of those involved in nursing care.
\end{abstract}

Keywords: Smell. Olfactory perception. Nursing care. Students, Nursing.

\section{Resumen}

El objetivo es identificar las percepciones y reacciones relacionadas al sentido del olfato en la atención de enfermería hospitalaria. Presenta los resultados de tres investigaciones de doctorado que centran sus datos sobre el sentido olfato a partir de la atención de enfermería hospitalaria en el trauma ortopédico, clínica quirúrgica y centro quirúrgico. Son estudios exploratorios, con enfoque cualitativo, utilizando los principios del método Sociopoético y Sentidos Sociocomunicantes. La transversalidad de los datos muestra el uso del olfato como herramienta para la atención, para evaluar el estado de higiene y limpieza del paciente y medio ambiente, e identifica rechazado por el mal olor que emana del paciente. Permiten reconocer esas reacciones a los olores de sus pacientes y el medio ambiente, para el reconocimiento de sus propias limitaciones a los estímulos y desarrollar mecanismos de respuesta que permiten la comodidad y seguridad de las personas involucradas en la atención.

Palabras-clave: Olfato. Percepción olfativa. Atención de Enfermería. Estudiantes de Enfermería.

\footnotetext{
Professora Associada I do Departamento de Enfermagem Médico-Cirúrgica da Escola de Enfermagem Anna Nery, da Universidade Federal do Rio de Janeiro. Doutora em Enfermagem. Rio de Janeiro - RJ. Brasil. E-mail stcaraujo@gmail.com; ²Professora Adjunta do Departamento de Enfermagem MédicoCirúrgica da Escola de Enfermagem Anna Nery, da Universidade Federal do Rio de Janeiro. Doutora em Enfermagem. Rio de Janeiro - RJ. Brasil. E-mail: lyscameron@gmail.com; ${ }^{3}$ Professora Assistente do Departamento de Enfermagem Médico-Cirúrgica da Escola de Enfermagem Anna Nery, da Universidade Federal do Rio de Janeiro. Doutoranda em Enfermagem. Rio de Janeiro - RJ. Brasil. E-mail: lilianfelippe@ig.com.br
} 


\section{INTRODUÇÃO}

Não existe maneira de compreender o mundo e o ser humano sem antes detectá-los por meio dos sentidos, sem antes torná-los perceptíveis aos sentidos comunicantes do corpo, que se manifestam no modo de olhar, falar, tocar, cheirar, ouvir e sentir com o coração. Os sentidos definem os limites da consciência, pois não esclarecem a vida em atos gritantes ou sutis, mas dividem a realidade em fatias vibrantes e as juntam em um padrão significativo. ${ }^{1-2}$

Os sentidos corporais permitem a compreensão do mundo pelo homem, e a sua relação com outros homens se dá através da comunicação, uma necessidade humana básica. Para isso, os sentidos corporais são fortes aliados como instrumento do cuidar que, associados ao conhecimento técnico e científico, garantem uma assistência holística e de qualidade. ${ }^{3}$

A atividade de enfermagem, requerente dos sentidos humanos, desenvolve-se em um cenário de múltiplos estímulos, e as percepções olfativas são fundamentais no espaço do cuidado hospitalar, considerado sua intensidade e constância no cotidiano. ${ }^{4}$

0 sentido olfato está fortemente relacionado às funções neurais emocionais e comportamentos primitivos. A olfação é um fenômeno subjetivo e, de todos os sentidos, 0 menos entendido. As regiões olfativas cerebrais estão entre as estruturas mais antigas do ser humano, e boa parte do restante do cérebro se desenvolve em torno desses primórdios olfativos. $\mathrm{Na}$ verdade, parte do cérebro que originalmente se relacionavam com a olfação evoluiu depois, originando estruturas cerebrais basais que no ser humano controlam as emoções e aspectos comportamentais. ${ }^{5}$

Pequena quantidade de agente estimulante no ar é suficiente para gerar uma sensação olfativa e pode disparar qualidades afetivas de prazer ou desagrado. Os receptores olfativos se adaptam em $50 \%$ dentro do primeiro segundo após a estimulação. Daí em diante, eles se adaptam muito pouco e lentamente. No entanto, as sensações olfativas se adaptam quase que à extinção dentro de aproximadamente um minuto, após entrarmos em um ambiente fortemente odorífero. Essa é uma adaptação psicológica, e admite-se que, após a deflagração do estímulo olfativo, o sistema nervoso central desenvolve gradativamente uma forte inibição por feedback para suprimir a transmissão dos sinais olfativos. ${ }^{5}$

0 ser humano é olfativo por natureza, interage com seu ambiente, percebendo e interpretando sensações odorantes de acordo com suas características estéticas, as quais poderão ser agradáveis, desagradáveis, confortáveis ou incomodas. As percepções e as sensações olfativas têm pertinência e significado como fenômeno presente na prática da enfermagem e, em especial, por sua diversidade, no ambiente hospitalar ${ }^{4}$.

Neste artigo, optamos por apresentar o olfato porque é um sentido que, através da memória traduzida pela percepção, define os limites da consciência do vivido, e, partindo da própria vivência prática de uma situação marcante, podemos acessar imagens impregnadas, retidas no inconsciente.

0 objetivo deste artigo é identificar as percepções e reações relacionadas ao sentido olfato em ambiente hospitalar, durante o cuidado de enfermagem prestado por futuros enfermeiros.

\section{MÉTODO}

Esta produção traz resultado de três pesquisas de doutorado que focalizam em seus dados o sentido olfato no cuidado de enfermagem hospitalar, em três especialidades hospitalares distintas, a saber: traumato-ortopedia, clínica cirúrgica e centro cirúrgico. A construção deste conhecimento é resultado de pesquisas exploratórias, de abordagem qualitativa, norteadas e analisadas à luz do referencial teórico dos princípios do método sociopoético ${ }^{6} \mathrm{e}$ dos sentidos sociocomunicantes do corpo ${ }^{2-3-7}$ e do modelo de enfrentamento ${ }^{8}$ e adaptação ${ }^{9}$ considerando os destaques apresentados na história natural dos sentidos ${ }^{1}$.

Em um ambiente de muitas subjetividades como é 0 hospital, dificilmente se encontra um espaço dialógico para refletir sobre os efeitos psicoafetivos gerados pelos cuidados prestados. Na enfermagem, a vivência sociopoética por ser mediada por ações livres, espontâneas e afetivas, possibilita e fomenta o diálogo necessário, a troca de informação, de energia, dos fluxos emocionais, colocando-nos como parceiros acessíveis, iguais e possibilitando a verbalização dos sentimentos.

Nesta vivência, podemos tornar conscientes as estruturas escondidas ou silenciadas no inconsciente, por desenvolver uma relação de ajuda-confiança: modo de comunicação que estabelece harmonia e cuidado e inclui o verbal, o não-verbal e o ouvir de modo empático. ${ }^{10}$ Desafiamos as pessoas nos grupos a discutirem as suas percepções sensoriais olfativas, com base nas experiências individuais. Também fizemos com que entendessem com o próprio corpo, com a pele e emoç̃̃es, o significado deste sentido no cuidado de enfermagem. ${ }^{2-3-7}$

Os sentidos sociocomunicantes do corpo que, historicamente vem contribuindo no caminho metodológico na linha de pesquisa sobre comunicação em enfermagem, em seu primórdio funcionou como categoria empírica. Contudo, através da replicação da técnica, nessas e em outras pesquisas, os sentidos vêm se consolidando como categoria teórico-analítica, aqui representada nas reflexões sobre o sentido olfato.

Destacamos que seja viável o compartilhamento, especialmente das características comuns dos participantes, pela convivência grupal, ao considerar e apontar os sentidos, as expressões e os movimentos do corpo, pondo em relevo o eu, a pessoa, o grupo, elementos essenciais para a escuta sensível e a compreensão do contexto, dos enfrentamentos e dos processos adaptativos presentes nas informações que eles compartilham sobre a sensibilidade olfativa. 
As oficinas grupais foram desenvolvidas durante 0 processo de ensino e aprendizagem do ciclo profissional de um curso de graduação em obstetrícia de uma universidade pública, na cidade do Rio de Janeiro, entre 2008 e 2010. Os grupos escolhidos aleatoriamente foram compostos por estudantes de diferentes turmas. Como critério de inclusão na pesquisa foi considerado aquele estudante que, na época, já havia cursado ou ainda cursava as experiências de aprendizagem relacionadas ao sentido olfato no cuidado prestado à clientela nos setores de traumato-ortopedia; de clínica cirúrgica e de centro cirúrgico. Participaram, em diferentes salas de aula, respectivamente 16, 12 e 26 estudantes.

Para o desenvolvimento dos projetos, obtivemos aprovação pelo Comitê de Ética em Pesquisa da EEAN/HESFA sob o protocolo $n^{\circ} 025 / 07$ e todos os participantes assinaram o Termo de Consentimento Livre e Esclarecido segundo a Resolução n 196/96, do Conselho Nacional de Saúde/MS, que fixa as diretrizes e normas regulamentadoras de pesquisa envolvendo seres humanos.

Para atender aos objetivos propostos, foram utilizadas técnicas com imagens que possibilitaram que o conhecimento sobre o sentido olfato no cuidado de enfermagem hospitalar fosse construído de forma individual e coletiva. 0 tema da oficina e a etapa de pensar, produzir dados e discutir sobre as experiências olfativas vivenciadas no cuidado de enfermagem foram conjugadas com as imagens de enfermeiras e pacientes projetadas do contexto hospitalar. Com duração média de uma hora, em três encontros sucessivos com os grupos, estas imagens foram escolhidas pelo efeito de acessar os registros do imaginário e por possibilitar a emergência, a tomada da consciência do que é geralmente escondido de maneira profunda ou superficial no imaginário e nos espaços de ensino e cuidado hospitalar. ${ }^{2-7}$ Considerando as atividades lúdicas relacionadas ao sentido olfato, projetadas através de imagens familiarizadas e relativas ao cuidado de alta complexidade, facilitamos as reflexões, as enunciações e a discussão individual e coletiva sobre o tema.

Todos os dados originados nas oficinas foram gravados, transcritos e reunidos para leitura e releitura do material bruto. Neste movimento de análise selecionamos palavras, expressões, frases, que traduziam convergência e localização das principais ideias temáticas sobre o sentido olfato no cuidado de enfermagem. As ideias complementares, opostas e semelhantes foram valorizadas, selecionadas e destacadas em negrito nos depoimentos ora apresentados nas principais transcrições dos sujeitos.

Para manter as características do contexto hospitalar que originaram as experiências olfativas, optou-se por apresentá-las em bloco, situando-as no próprio setor que as contextualiza. Depois de eleitas, as unidades temáticas foram analisadas à luz dos referenciais teóricos e apontaram uma ação diagnóstica olfativa com efeitos sobre o padrão de comunicação e cuidado, limitações, reações comportamentais e estratégias para enfrentar e corrigir condutas que incluam no cuidado o conforto, tanto para o paciente como para o profissional.

\section{RESULTADOS}

Atributos próprios da relação humana são fundamentais na construção de vínculo entre a enfermeira e o cliente durante cuidado e, por isso, é necessário considerá-los como aspectos essenciais na relação entre seres humanos e ao processo de cuidar. ${ }^{11-12} 0$ conceito de corpo com o qual trabalhamos implica a expressão do sujeito e, também, a necessária manutenção da identidade do cliente no espaço social hospitalar, principalmente quando vivencia o cuidado de enfermagem. ${ }^{13}$

A complexidade do contexto hospitalar é desvelada apontando as singularidades e as convergências pessoais nas experiências vividas pelos grupos de estudantes de Enfermagem durante o cuidado hospitalar. A técnica construída e aplicada, valorizando o sentido olfato, funcionou como um excelente dispositivo de diálogo consolidando uma metodologia emergente de ensinar, cuidar e pesquisar e cujo resultado é a rica produção de muitas subjetividades e de compreensão de como sentimos e reagimos olfativamente no cuidado de enfermagem que prestamos.

Ao pensar no corpo do cuidado a partir de imagens, criamos instâncias de subjetivação que cristalizam pensamentos, estabelecendo dimensões estéticas da prática. Isso possibilita a transferência de entendimento do cuidado hospitalar a partir de quem proporciona esse cuidado.

A seguir, apresentamos alguns dados que emergiram nas oficinas sobre o cuidado hospitalar sobre o sentido olfato. Em itálico estão alguns depoimentos dos grupos por especialidade e, em negrito, os fragmentos temáticos, considerados para a análise:

\section{Traumato-Ortopedia:}

[...] reconhecer qual é o odor patológico e qual éo odor fisiológico, das secreções, das fezes, da pele, da urina, do mau hálito, das feridas. Isso tudo vai interferir no meu cuidado. $(B, D)$

É através do odor que a gente consegue identificar alguns distúrbios fisiológicos. Então, a gente consegue sentir através do odor que alguma coisa pode estar errada como paciente. (L, MS)

0 odor, muitas vezes deixa a autoimagem e a autoestima do paciente baixas. Tem a questão da vergonha no caso de que muitos pacientes ficam sem evacuar por vergonha, por vergonha do cheiro. $\mathrm{Na}$ questão da ferida, muitos pacientes ficam constrangidos em trocar aquele curativo sabendo que quando abrir aquele curativo vai exalar um odor 
fétido. Então eu acho que o odor está muito ligado à autoimagem do paciente. (M, RM)

[...] depois que a gente vai lá e faz o cuidado, o paciente fica com um odor agradável, perfumado. Ele fica alegre porque ninguém gosta de ficar sujo. E ele fica estável. Você consegue estabilizá-lo. Porque às vezes ele está angustiado, ele está alterado, e depois que você dá o banho, ele dorme, melhora o humor, a satisfação. Fica assim: agora eu estou bem. (L, MS)

A gente chega e sente aquele cheiro de sangue, cheiro de sujeira, cheiro de xixi, porque o banheiro está sujo, cheiro de suor do paciente e cheiro das feridas. (T, MP)

[...] eu acho importante que na hora que a gente for fazer o cuidado, controlasse essa cara de nojo, essa cara de que a gente vai vomitar, porque ânsia de vômito todo mundo tem. (RA, $\mathrm{PP})$

[...] colocar a mão no nariz, que dá vontade mesmo de botar, eu mesma já fiz. Infelizmente, eu estou nesse grupo. Mas eu também posso fazer? Mas eu também vou lá, e dou banho, e vou ajudar. (RC, GS)

\section{Clínica Cirúrgica:}

O cheiro de vômito, diarreia me incomodam bastante. Eu sempre fui muito voltada para o cheiro, tanto que as minhas memórias estão sempre relacionadas a algum perfume, o cheiro de alguma situação. Eu sempre fui muito de "cheiro" e nessas situações os cheiros são desagradáveis. (T)

[...] meu problema é com vômito, também. Acho que com todas as secreções, é o cheiro. Eu tenho que prender minha respiração pra ajudar a pessoa, se não eu vou junto. (M)

Trocar a comadre depois do paciente ter evacuado bastante [...] é a única coisa que me desagrada, principalmente quando tem cheiro muito forte. Só que você não pode demonstrar para o paciente. Eu levei a comadre para o banheiro e voltei como se nada tivesse acontecido. Foi desagradável. A tática é que eu tento pensar em outra coisa, me concentrar. (I)
Acho que as fezes mais me desagradam por ter a sensação de que é sujo e o vômito também, pelo cheiro, pelo aspecto. Eu procuro fazer tudo rápido para que a pessoa não perceba que eu não estou me sentindo bem naquele momento. Eu faço tudo rápido, limpo rápido, porque quando eu faço tudo rápido acaba aquilo e o nojo passa. (A)

Eu senti o cheiro de uma secreção traqueobrônquica que foi terrível! Quando a gente foi aspirar estava muito fétido. Foi a vez que mais me incomodou. (J)

Ao cuidar de um cliente com uma deiscência, 0 cheiro não era nada agradável, a ferida estava contaminada e o cheiro se misturava ao cheiro da urina. Senti por um bom tempo este cheiro, mesmo depois de estar longe do cliente. (R)

\section{Centro Cirúrgico:}

0 paciente botava a mão na frente da boca. Eu achava aquilo engraçado, porque, quando ele chegou, eu já tinha me dado conta daquela história toda. Enão era uma coisa muito forte, o cheiro, 0 odor não era um odor muito forte, e ele botava a mão, o tempo todo, na frente e isso me dificultava entender o que ele estava falando. Ele falava baixo e ainda botava a mão, aí eu desconfiei que ele estivesse com mau hálito. (I)

O único odor que eu senti hoje e que me chamou bastante a atenção foi o do paciente que recebemos, que ia ser submetido a uma amputação na coxa direita. Então, na sala de RPO (Recepção Pré-Operatória), teve um cheiro que me marcou muito, e eu não sabia de onde estava vindo aquele cheiro. [...]Aí, eu fui ver de onde estava vindo aquele cheiro. Bem, era, devia ser uma úlcera, né?! 0 curativo estava com secreção, uma secreção amarronzada e o odor muito forte, e foi dali que eu senti o cheiro. (G)

Ele falava comigo e botava a mão na frente da boca. Eu não sei se ele achava que estava com mau hálito. Ele estava com cheiro de enfermaria. (H)

Eu tenho um problema com o odor, por que eu tenho rinite alérgica. Constantemente meu nariz está congestionado. Difícil perceber algum odor. $E$ hoje, a primeira coisa quando ele entrou, foi sentir o cheiro. (G) 


\section{DISCUSSÃO}

A educação do futuro enfermeiro deve garantir uma prática pedagógica que leve em conta as suas potencialidades, ${ }^{14}$ e dialogar sobre um olhar acurado, que mora e demora no tempo, possibilita para o estudante também compreender a profundidade das suas percepções e reações ao outro e ao ambiente.

As palavras latinas contemplarie meditarisignificam, respectivamente, olhar atentamente para, considerar. Considerari significa examinar com cuidado e respeito aquilo que se expressa, o que se apresenta na criação e arte do cuidado como um ato gritantemente silencioso ou, pelo menos, sem alardes e barulhos não adequados ${ }^{12}$.

Durante a vida, seguimos acumulando experiências olfativas que, com suas características e estímulos, consolidam o imaginário olfativo dos fenômenos odorantes. Estes odores podem ser emanações que acompanham o ser humano, e algumas situações, apresentam-se desagradáveis ao sentido, com sensação de desconfor to geral. Nestes casos, quando possível, temos as medidas adotadas, que geralmente são de contenção, dispersão ou eliminação imediata dos mesmos.

A maior compreensão das emanações odorantes poderá favorecer, no diagnóstico e no cuidado de enfermagem, a vigilância da qualidade ambiental e terapêutica ${ }^{4}$. Quando compreendemos a sua importância, a ação de bom grado, de boa vontade, é um ato essencial, não nocivo e, assim, um ato de cuidado. ${ }^{12} \mathrm{~A}$ base inicial refere-se à disposição de olhar, refletir e encontrar significados através da própria análise dos processos vivenciados no contexto do cuidado. ${ }^{8}$

Os cuidados de enfermagem às pessoas hospitalizadas estão impregnados de odores que, de alguma forma, têm importantes significados e produzem reações de diferentes intensidades. 0 exame físico de enfermagem é 0 exame para o cuidado de enfermagem e no ambiente hospitalar ele deve se valer de observação participante, aproximativa, inclusiva, e não distanciadora. ${ }^{12}$

Destacamos, como base importante no enfrentamento e na adaptação diante dos desafios olfativos, a riqueza humana de compartilhar valores, crenças e metas, pois a perspectiva filosófica interfere naquilo sobre o qual a pessoa se interessa, se dá conta e pode compreender. 8

Portanto, os cheiros que contaminam simbolicamente e criam imagens que se formam no imaginário das pessoas, ao serem considerados no cuidado, devem ampliar os aspectos relacionais, intuitivos, expressivos, afetivos, dialógicos e analíticos em favor do ato de cuidar integral da pessoa cuidada. Trajetórias e memórias de corpo são unidades de vida e, do ponto de vista conceitual, superam as noções e os conceitos de sujeito e de objeto-coisas. ${ }^{12}$

Os estímulos olfativos podem gerar memórias residuais. As memórias, por sua vez, podem funcionar como fatores que, na maioria das vezes, são desconhecidos por nós.
Este sentido nos acompanha em boa parte de nossa vida e temos nos valido durante as atividades profissionais, tanto de ensino, como na prática assistencial de enfermagem, de ilustrálo em situações cujo paciente é dependente integralmente dos nossos cuidados para atendimento de suas necessidades básicas.

Muitas vezes, como os efeitos gerados pela utilização olfativa não são investigados no contexto do pensar/fazer, fazer/ pensando, seus desdobramentos também ficam incompreendidos por aqueles que com eles convivem. Vivenciar o cuidado de forma consciente é também reconhecer e considerar que nesta relação de cuidado o ser humano têm suas dimensões subjetivas. Para tal, precisamos ao mesmo tempo valorizar as experiências humanas e considerá-las como a central do conhecimento ${ }^{8}$.

Influenciadores no mecanismo de adaptação, o estímulo/efeito gerado por esse sentido pode ser: uma expectativa, uma expressão, um valor, uma atitude, uma crença, produto de experiências passadas. ${ }^{9}$ E precisamos conhecer como estamos atuando nesta situação em que as interdições do corpo do paciente também desencadeiam reações no corpo de quem presta o cuidado de enfermagem. Reafirmamos o propósito comum do ser humano, para o cuidado de conforto, como aquele que deve considerar a totalidade do ser, conformada por partes que se mobilizam com um propósito e não simplesmente por uma relação causa-efeito. ${ }^{8}$

0 sentido olfato é o sentido mudo, o que não tem palavras, não necessita de tradutor; é o mais direto dos nossos sentidos, e seu efeito é imediato. Por isso, os odores nos tocam profundamente, ${ }^{1}$ os cheiros quando emanados atraem, repelem, envolvem, embriagam, impregnam, excitam e entorpecem. ${ }^{4}$ Interconectando a forma de contemplar e considerar, buscamos um olhar atento para examinar, com cuidado e respeito, tanto as expressões oriundas das sensações olfativas, do próprio corpo, como as expressões ou memórias da pessoa cuidada. ${ }^{11}$ Os contextos são estímulos que estão presentes nesta situação e podem funcionar como o centro de atenção e de consumo de energia adicional. ${ }^{9}$ Esses influenciam na forma como a pessoa pode enfrentar o estímulo focal e a relação entre o enfermeiro e o paciente sob seu cuidado.

Ao analisar a percepção dos estudantes em relação ao sentido olfato, constatamos que gerou muita discussão. De modo geral, a enfermeira consegue enfrentar certas situações sem demonstrar constrangimento. Mas, algumas vezes, a entonação de sua voz pode demonstrar certa repulsa. ${ }^{7}$ Os odores são percebidos de forma marcante, se espalham rapidamente, não se restringem ao nosso redor e conseguem invadir vários ambientes distantes. Mas, seja qual for o limite, a relação no cuidado é para superá-lo no tempo, no limite, na maneira de ser, no estado, no modo, na distribuição entre, na forma de, na finalidade de uma e de outra forma, para alcançar uma situação dentro daquele limite superável. ${ }^{11}$ 
0 olfato é utilizado pelos estudantes como eficiente aliado para identificar alterações de saúde e de higiene. Eles entendem que os maus odores são sinais de que alguma coisa errada está acontecendo ao paciente, seja pela falta de higiene ou por alteraç̃oes físicas significativas da doença, e que necessitam de rápida identificação e intervenção. ${ }^{1} 0$ infragmentável sentido corporal olfativo, com expressão e criação de sentidos e representações, de cognição, da produção de imagens, gera poder e produtos de subjetividades, instituído e instituinte; faz movimentos de mudança; corpo real-emocional (objetivo, subjetivo), pois somos o que lembramos - corpo memória. $^{12}$

0 corpo para o cuidado de enfermagem é, a um só tempo, como é na realidade, uno e integralmente biológico, emocional, pessoal, político, espiritual, social, cósmico, psicológico, enfim, um corpo histórico e profundo, ${ }^{11}$ e os estudantes, ao relacionarem limpeza ao cuidado, estabelecem ligação entre o cuidado, o confor to e o bem-estar do paciente à higiene corporal e ambiental. Apesar de os hábitos de higiene serem variáveis entre as pessoas, em um ambiente hospitalar, odores corporais e ambientais desagradáveis remetem imediatamente ao deficiente cuidado de enfermagem, o que é entendido como inadmissível em um local onde se propõe restabelecer a saúde.

Os odores provenientes da restrição à mobilização, secreção, sangue, fezes, urina, vômito, feridas, entre outros, são identificados como potentes fontes de desconforto para os pacientes e para a equipe. A resolução para esse problema é, na opinião do estudante, manter adequadas condições de higiene do corpo e fazer reavaliações constantes.

Vale destacar que as expressões: cuidado de e em enfermagem podem refletir em qual dos limites as preposições se dirigem na expressão do cuidado a pessoas dependentes deles. Podemos destacar que, quando o enfermeiro cuida, ambos (enfermeiro e cuidado) entram em cumplicidade, e, neste contato, variamos a posição $0^{12}$ tanto de um, quanto de outro; podemos estar embaixo, no meio, em cima, dentro dos limites ou no seu interior, e, independente de qual seja o tamanho ou a condição volátil, o que se espera nessa relação é a bilateralidade de seu efeito, tanto de quem cuida, quanto de quem é cuidado.

Como os odores desagradáveis despertam desconforto, o comportamento mais comum é se afastar da fonte. Mesmo sentindo repulsa pelo odor que provenha do paciente, os estudantes procuram não manifestá-la próximo a ele para não ofendê-lo e por entenderem que, na maior parte das vezes, não depende do paciente a resolução do problema, e sim da enfermagem. Avançando a atenção para preposição de, relembramos suas significações. A preposição latina de significa procedente de, a partir de, depois de, à custa de, feito de, por causa de, entre outras. ${ }^{12}$

Considerando que 0 ato de comunicar engloba formas verbais e não verbais e que a forma como estas se apresentam afetam as relações interpessoais, há a necessidade também de compreender as situações que limitam e/ou empobrecem o processo comunicativo diante do cuidado mediado pelo sentido olfato. $^{7}$

0 estudo aponta que os estudantes nem sempre sabem lidar com essas situações e podem acabar expressando determinadas reações aversivas, que sofrem crítica imediata, a si mesmos ou a outros e, de alguma forma, buscam mecanismos para esconder ou sublimar essas reações reconhecidas por eles como inaceitáveis na enfermagem. As manifestações cinésicas (dos movimentos) e proxêmicas (posição definida entre os corpos na interação), tanto de repulsa de estudantes como de membros da equipe, não são admitidas próximas ao paciente. Situações de vergonha e autoestima diminuída pelos odores provenientes do problema de saúde, excreções ou secreções, levam à manifestação de discrição e solidariedade à condição do paciente.

Em um ambiente hospitalar, existem emanações odorantes que podem ter múltiplos significados como a presença de um agente biológico, condição de risco ou pouca higiene ambiental. Estudos acerca das percepções olfativas presentes no ambiente do cuidado, suas origens e fatores desencadeantes poderão contribuir para a qualidade da enfermagem e maior conforto e segurança para as pessoas deste espaço ou contexto. ${ }^{14}$

Para a enfermagem, os odores pessoais e ambientais podem ter muitos significados. As experiências vividas com a riqueza dos sentidos sociocomunicantes do corpo comprovaram como os sentidos se somam à interação, à afetividade e ao inconsciente individual, passando de uma situação singular para uma situação plural com significaç̃̃es múltiplas. Importante é valorizar essas percepções, as sensações e as reações delas advindas, durante a prestação dos cuidados. Esse processo só é possível quando a tomada de consciência nos permite enxergar os mecanismos de enfrentamento e adaptação, que podem ser ajustáveis no cuidado diário de enfermagem.

\section{CONSIDERAÇÕES FINAIS}

Este estudo investigou a importância do olfato como instrumento fundamental para captar, avaliar e subsidiar o cuidado de enfermagem à clientela hospitalizada em três diferentes especialidades, expondo a forma de contemplar com criatividade e engenhosidade as interdições de cuidado sensibilizadoras do sentido olfato e, com uma dose maior de segurança, as situações que geram desconforto.

Instituímos o diálogo e formas de compreensão sobre os odores, os conflitos, as contradições, as angústias, as estratégias e a importância desses elementos no cuidado de enfermagem à clientela hospitalizada. Promovemos um espaço no qual todos puderam transmitir o que estavam sentindo, sobre a percepção olfativa e seus usos e interferências durante o cuidado prestado, valorizando a subjetividade a partir dos 
sentidos do corpo e das manifestações do imaginário dos sujeitos. Por ser um método que valoriza a expressão, os estudantes foram capazes de (re)significar a utilização do próprio sentido olfato no cuidado de enfermagem.

Os estudantes de graduação utilizam o sentido olfato como instrumento para o cuidado, para identificar algumas alterações no estado físico do paciente e para avaliar o estado de higiene do paciente e limpeza do ambiente. No entanto, lidar com os odores que emanam do corpo do outro, para alguns estudantes, pode ser considerada uma experiência negativa. Expressões de nojo ou repulsa, por mais que sejam difíceis de evitar, são fortemente criticadas, em si e nos outros, por serem entendidas como inaceitáveis se ocorrerem durante o cuidado.

Esse tipo de comportamento é compreendido por eles como indo de encontro ao que entendem como o correto e aceitável, sem repulsas e sem expressão de desagrado de quem se propõe a cuidar de uma pessoa doente. 0 ideal, segundo eles, é que se expressem somente comportamentos identificados como condizentes e apropriados com os valores da profissão, e a manifestação de repulsa pode significar um importante comprometimento na relação de ajuda.

Possibilitar que os futuros enfermeiros conheçam e reconheçam essas reações aos odores de seus pacientes e suas atitudes neste cuidado amplia o reconhecimento de suas próprias limitações aos estímulos e descortina estratégias que Ihes permitam fazê-lo com cautela, com mecanismos de enfrentamento e adaptação cujas respostas objetivam o conforto e a segurança dos envolvidos no cuidado.
7.Saes SC, Araújo STC. 0 cuidado de enfermagem através dos sentidos corporais do paciente em diálise peritoneal: uma abordagem sociopoética. Esc Anna Nery. 2004; 8 (2): 259-66.

8.Roy C. El modelo de adaptación de Roy fundamentación histórica y filosófica. Maria Del Carmen Gutiérrez. In: Adaptación y cuidado en el ser humano: uma visión de enfermería. Bogotá: Ed El Manual Moderno, Universidad de La Saban; 2007. p.1-12.

9.Agudelo MCG. Proceso de afrontamiento y adaptación. Maria Del Carmen Gutiérrez. In: Adaptación y cuidado en el ser humano: uma visión de enfermería. Bogotá: Ed El Manual Moderno, Universidad de La Saban; 2007. p.13-25.

10.Galbreath JG. Sister Callista Roy. In: George JB. Teorias de enfermagem: os fundamentos para a prática profissional. Porto Alegre: Artes Médicas; 1993. p.206-26.

11.Silva DC, Figueiredo PA. Tecnologias leves em saúde e sua relação com o cuidado de enfermagem hospitalar. Esc Anna Nery. 2008; 12(2): 29198

12.Figueiredo NMA, Machado WCA. Corpo e saúde. Condutas clínicas de cuidar. Rio de Janeiro: Águia Dourada; 2009.

13.Ferreira MA, Figueiredo NMA, Arruda A, Alvim NAT. Cuidados fundamentais de enfermagem na ótica do cliente: uma contribuição para a Enfermagem Fundamental. Esc Anna Nery. 2002; 6 (3): 387-96.

14.Mostardeiro SCTS. Refletindo sobre a formação do enfermeiro: a prática docente a partir do imaginário pedagógico. Esc Anna Nery. 2004; 8(1):21-8.

\section{REFERÊNCIAS}

1.Ackerman D. História natural dos sentidos. São Paulo: Berthand Brasil; 1992.

2.Araújo STC. Os sentidos corporais dos estudantes no aprendizado da comunicação não-verbal do cliente na recepção pré-operatória: uma semiologia da expressão através da Sociopoética [tese]. Rio de Janeiro: EEAN/UFRJ; 2000.

3.Cameron LE, Araújo STC. Vision as an instrument of perception in trauma and orthopedic nursing care. Rev Esc Enferm USP. 2011; 45(1): 95-9.

4.Wosny AM, Erdmann AL, Belli Filho P, Leite JL. The aesthetics of smells: the sense of smell and nursing. Rev Latino-am Enfermagem. 2008; 16(2): 320-23.

5.Hall JE, Guyton AC. Guyton \& Hall- Tratado de Fisiologia Médica. $9^{a}$ ed. Rio de Janeiro: Guanabara Koogan; 1997. 